\title{
Dynamic Modeling a of Phosphoric Acid Fuel Cell (PAFC) and Its Power Conditioning System
}

\author{
M. A. Tanni, Md Arifujjaman, and M. T. Iqbal
}

\begin{abstract}
This paper presents the dynamics of a phosphoric acid fuel cell (PAFC) and its associated power electronics. The modeling of the power conditioning system for phosphoric acid fuel cell is discussed here. This model is based on empirical equations. The simulation is done using Matlab/Simulink and its Power System Blockset (PSB). This model mathematically calculates cell output voltages and their consequent losses. It also calculates the ac output from the system by simulating an inverter dc input from the fuel stacks. The V-I curves and dynamics can be observed. The effects of variation in outputs for different inputs can also be observed. This model is easy to understand and it requires less computational time.
\end{abstract}

Index Terms-Distributed generation, dynamic modeling and simulation, phosphoric acid fuel cell, power conditioning system.

\section{INTRODUCTION}

Recently alternative or renewable energy is becoming more popular because of increasing energy consumption. People are also becoming aware of environment impact and declining fossil fuels. Common alternate energy sources are fuel cells, wind turbines, micro-turbines, photovoltaic etc. These are also referred as distributed generation (DG). Fuel cells have drawn more attraction from different distributed generation since it has the potential capability of providing both heat and power [1].

A fuel cell (FC) is an electrochemical device that converts the chemical energy of the fuel directly into electrical energy. Fuel cells have a low environmental impact and operate silently in practical situations with high efficiency and long lifetime. So they can represent a very good option as a DG [2].

A power conditioning stage is essential to produce commercial ac power since the output of a fuel cell is dc electricity [3]. So fuel cell plants can produce this ac power. Generally there are three major subsystems in a fuel cell plant which are a reactant supply subsystem to convert natural gas to a hydrogen-rich gaseous fuel, a power section subsystem including a thermal management assembly to generate dc power and a power conditioning subsystem to convert the dc power generated in the power section subsystem to ac power [4]. Fig. 1 shows the process.

According to the type of electrolyte used, the most

Manuscript received October 9, 2012; revised January 17, 2013.

M. A. Tanni is with Memorial University of Newfoundland, Canada (e-mail: mat078@mun.ca).

Md Arifujjaman is with UTC Power, South Windsor, CT, USA (Md.Arifujjaman@UTCPower.com).

M. T. Iqbal is with the Department of Engineering and Applied Science, Memorial University of Newfoundland, Canada (email: tariq@mun.ca). common fuel cells are: phosphoric acid fuel cells (PAFC), alkaline fuel cells (AFC), molten carbonate fuel cells (MCFC), solid oxide fuel cells (SOFC) and proton exchange membrane fuel cells (PEMFC).

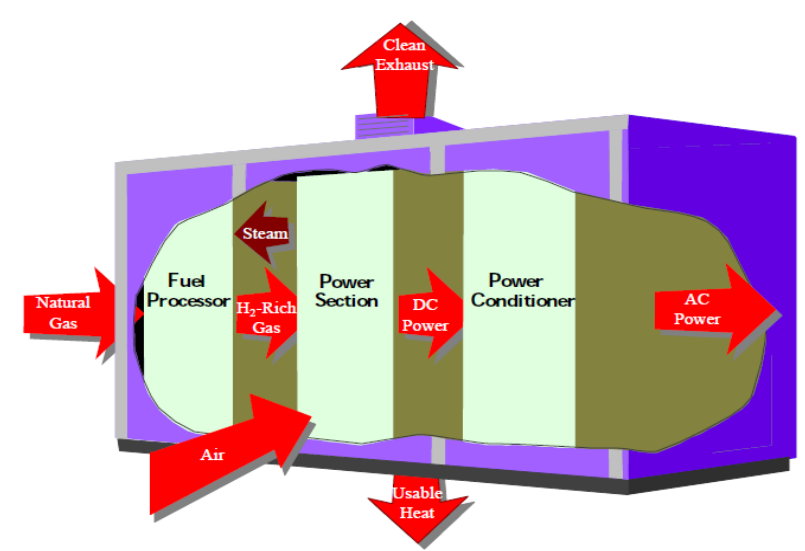

Fig. 1. Fuel Cell Power Plant Major Processes [5], (P: 1-7)

Among them, PAFC has one of the most advanced technologies available commercially. It is possible to improve the performance of a fuel cell by changing the operating variables (e.g. pressure, temperature, gas composition, current density etc.). It is important to select an operating point (cell voltage and related current density) of a fuel cell till the system requirements are satisfied [6].

This paper represents a model of the last two subsystems of Fig. 1. A dynamic modeling of phosphoric acid fuel cell (PAFC) system including dc to ac power conversion is proposed here. The model is based on empirical equations. This model includes fuel stacks to produce dc power and a dc to ac inverter to produce ac power. The model is validated by Sim Power Systems (SPS) block set of Matlab/Simulink. Section 2 describes the mathematical model, section 3 describes the dynamic model, section 4 shows the simulation results and discussions, and section 5 concludes the paper.

\section{MATHEMATiCAL Modeling}

Since mathematical modeling gives the idea of valuable insight into the electrochemistry of the fuel cell and the processes that take place in the system, it can be considered as a basic tool in the development of fuel cells [6].

In this paper, the model of PAFC investigates the appropriate load according to the power demand. It also shows the IV curves and values of dc and ac voltage, current and power. The system consists of three PAFC stacks and each stack contains 376 individual cells. The dc output power is converted to ac. The basic block diagram of the proposed model is presented in Fig. 2. 


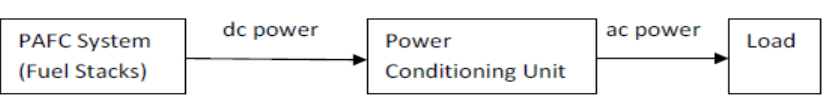

Fig. 2. Basic block diagram of the PAFC model

The mathematical modeling of a PAFC is the foundation for the modeling of the whole PAFC system. The mathematical modeling of an individual PAFC includes Nernst potential, activation loss, ohmic loss and concentration loss. The overview is shown in Fig. 3 below.

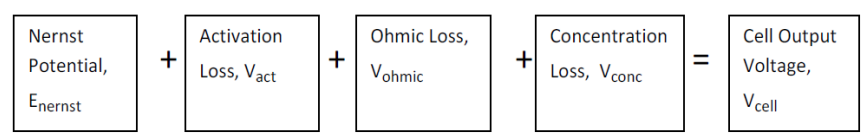

Fig. 3. Block diagram of an individual PAFC
The equation format of fig. 3 can be expressed as below [6],

$$
V_{\text {Cell }}=E_{\text {nernst }}+V_{\text {act }}+V_{\text {ohmic }}+V_{\text {conc }}
$$

\section{A. Nernst Potential}

The thermodynamic potential can be obtained at thermodynamic balance. The Nernst potential is the modified equation to express this voltage. At standard condition $(298.15 \mathrm{~K}, 1 \mathrm{~atm})$, the overall reaction includes hydrogen, oxygen and vapor to produce a thermodynamic potential [7].

$$
E_{\text {nernst }}=E^{0}+\frac{R T}{n F} \ln \left[\frac{p^{\prime} H 2\left(p^{\prime} O 2\right)^{0.5}}{p^{\prime} H 2 O}\right]
$$

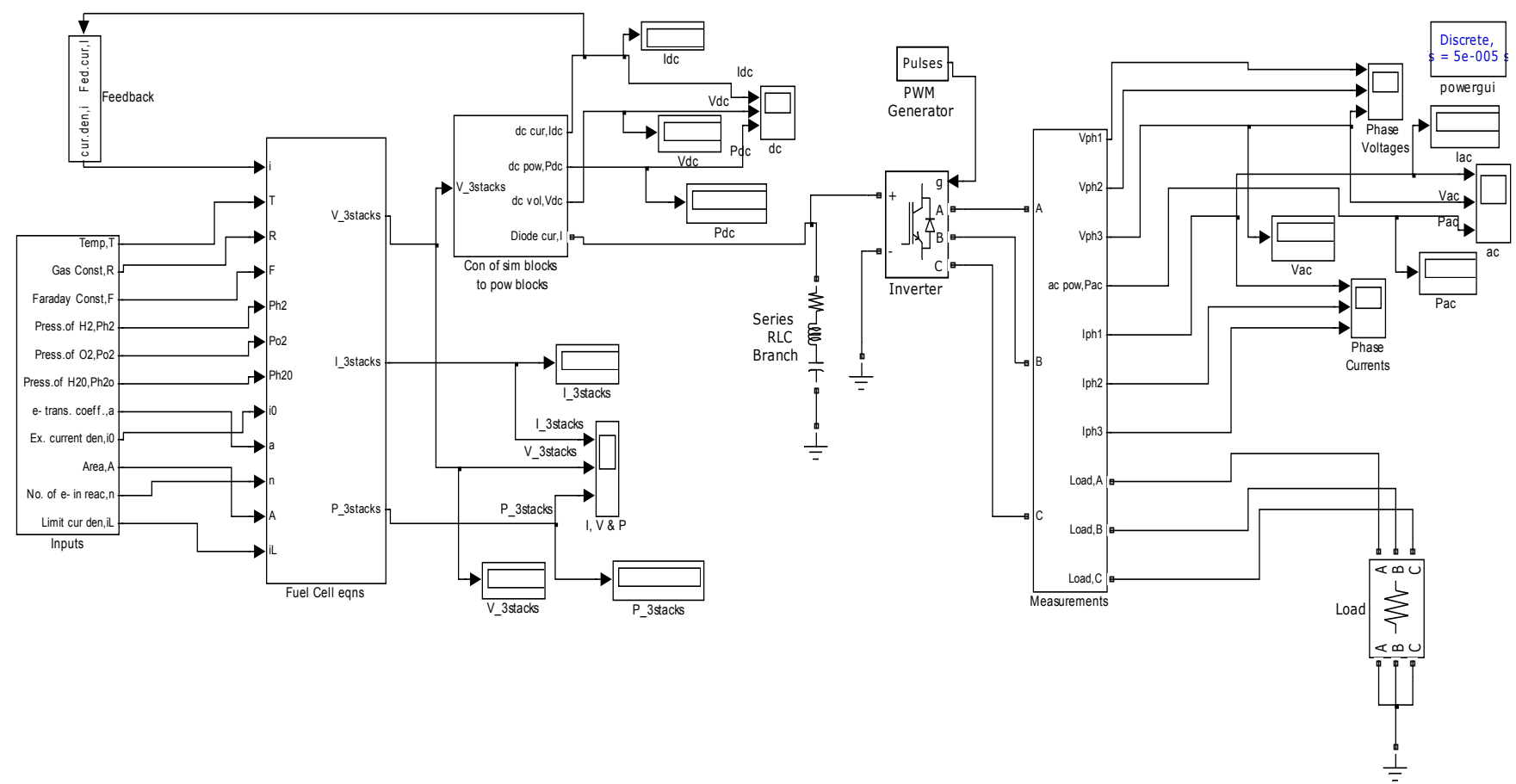

Fig. 4. Dynamic Model of PAFC

Here $E^{0}$ represents the reference potential at unity cavity $\left(1.229 \mathrm{~V}\right.$ at standard state), $p_{\mathrm{H} 2}^{\prime}, p_{\mathrm{O} 2}^{\prime}$ and $p_{\mathrm{H} 2 \mathrm{O}}^{\prime}$ are the hydrogen, oxygen and vapor partial pressures (atm), respectively. Moreover, $T$ is the cell temperature $(\mathrm{K}), R$ is the universal gas constant $\left(8.31441 \mathrm{~J} \mathrm{~mol}^{-1} \mathrm{~K}^{-1}\right), F$ is the Faraday constant $\left(96484.56 \mathrm{C} \mathrm{mol}^{-1}\right)$ and $n$ is the number of electrons participating in the reaction [7].

\section{B. Activation Loss}

The activation energy involves both the electrical and chemical reactions. The similarity between them can be overcome by the reacting species. The voltage drop caused by activation losses on a particular electrode under specific conditions can be controlled by the rate parameters and activation energy of one or more rate limiting reaction steps. The equation for activation polarization is described by the following equation [5].

$$
V_{a c t}=-\frac{R T}{\alpha n F} \ln \frac{i}{i_{0}}
$$

where $\alpha$ is the electron transfer coefficient of the reaction at the electrode being addressed, $i$ is the current density and $i_{0}$ is the exchange current density.

\section{Ohmic Loss}

Ohmic loss occurs because of resistance of flowing ions in the electrolyte and through the electrode. This loss can be reduced by decreasing the electrode separation and enhancing the ionic conductivity of the electrolyte [5], (P:2-12). The ohmic over voltage is given by equation (4) [7].

$$
V_{\text {ohmic }}=-I R_{\text {int }}
$$

Here $I$ is the electrical current and $R_{i n t}$ is the internal resistance. The equation of $R_{i n t}$ is developed empirically for the proposed model based on some experimental data keeping the temperature fixed to $451 \mathrm{~K}\left(178{ }^{0} \mathrm{C}\right)$. The equation of $R_{\text {int }}$ can be expressed as below,

$$
R_{\text {int }}=0.0652 I^{-0.819}
$$




\section{Concentration Loss}

A reactant is consumed at the electrode by electrochemical reaction where it is often diluted by the products. Concentration loss is the result of this incident. The equation of concentration can be written as [5], (P: 2-16).

$$
V_{\text {conc }}=\frac{R T}{n F} \ln \left(1-\frac{i}{i_{L}}\right)
$$

where $i_{L}$ is the limiting current density.

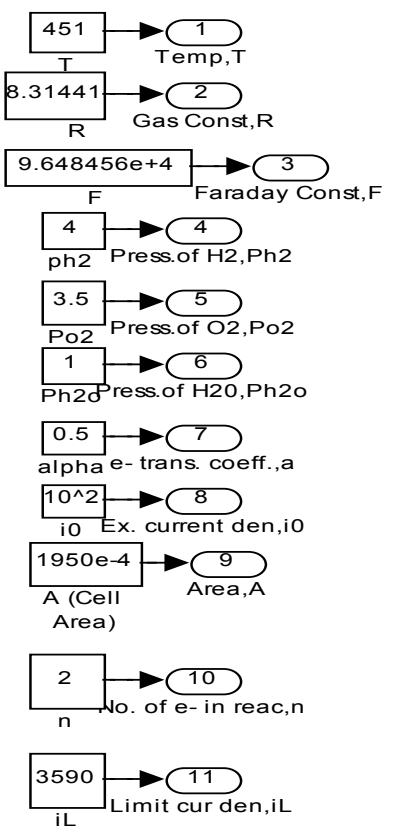

Fig. 5. 'Inputs' subsystem block

The mathematical modeling of a single PAFC stack follows equation (7) [7],

$$
V_{\text {stack }}=N V_{\text {cell }}
$$

where $N$ is the number of fuel cell and $V_{\text {stack }}$ is the stack voltage for a PAFC.

\section{DYNAMIC MODELING}

The mathematical expressions for the fuel-cell system and power conditioning system are modeled in the Matlab-Simulink environment. The dynamic model of PAFC is given in Fig. 4.

From Fig. 4, the dynamic modeling of the PAFC system including power conditioning system can be simulated. The 'Inputs', 'Feedback', 'Fuel Cell eqns', 'Con of sim blocks to pow blocks' \& 'Measurements' block are subsystem blocks. The 'Inputs' block contains all inputs to the model.

Fig. 5 shows the inputs of the model which can be observed in table I clearly.

The 'Fuel Cell eqns' sybsystem block contains all fuel cell equations related to the model. This block simulates equation (1) to equation (7). The PAFC system contains 3 fuel stacks and each stack contains 376 fuel cells. All of the equations are imposed on each fuel cell of the PAFC system. The final equation of the PAFC system can be expressed as,

$$
V_{\text {_stack }}=3 \times \text { Single_Fuel_Stack }
$$

Fig. 6 shows the 'Fuel Cell eqns' subsystem block. The outputs (current, voltage \& power of three stacks) of this block can be observed through the display blocks and the curves can be investigated through the 'I, V \& P' scope block. The output 'V_3stacks' is connected to the 'Con of sim blocks to pow blocks' subsystem block.

TABLE I: INPUT PARAMETER VALUES OF The PAFC DyNAMIC MODEL

\begin{tabular}{|l|l|}
\hline Parameter Name & Parameter Value \\
\hline Temperature, $T$ & $451 \mathrm{~K}$ \\
\hline Gas Constant, $R$ & $8.31441 \mathrm{~J} \mathrm{~mol}^{-1} \mathrm{~K}^{-1}$ \\
\hline Faraday Constant, $F$ & $96484.56 \mathrm{C} \mathrm{mol}^{-1}$ \\
\hline Partial pressure of hydrogen, $p_{H 2}$ & $4 \mathrm{~atm}$ \\
\hline Partial pressure of oxygen, $p_{O 2}$ & $3.5 \mathrm{~atm}$ \\
\hline Partial pressure of vapor, $p_{H 2 O}$ & $1 \mathrm{~atm}$ \\
\hline Electron transfer coefficient, $\alpha$ & 0.5 \\
\hline Exchange current density, $i_{0}$ & $10^{2} \mathrm{~A} \mathrm{~m}^{-2}$ \\
\hline Cell area, $A$ & $0.1950 \mathrm{~m}^{2}$ \\
\hline $\begin{array}{l}\text { Number of electrons participating in the } \\
\text { reaction, } n\end{array}$ & 2 \\
\hline Limiting current density, $i_{L}$ & $3590 \mathrm{~A} \mathrm{~m}^{-2}$ \\
\hline
\end{tabular}

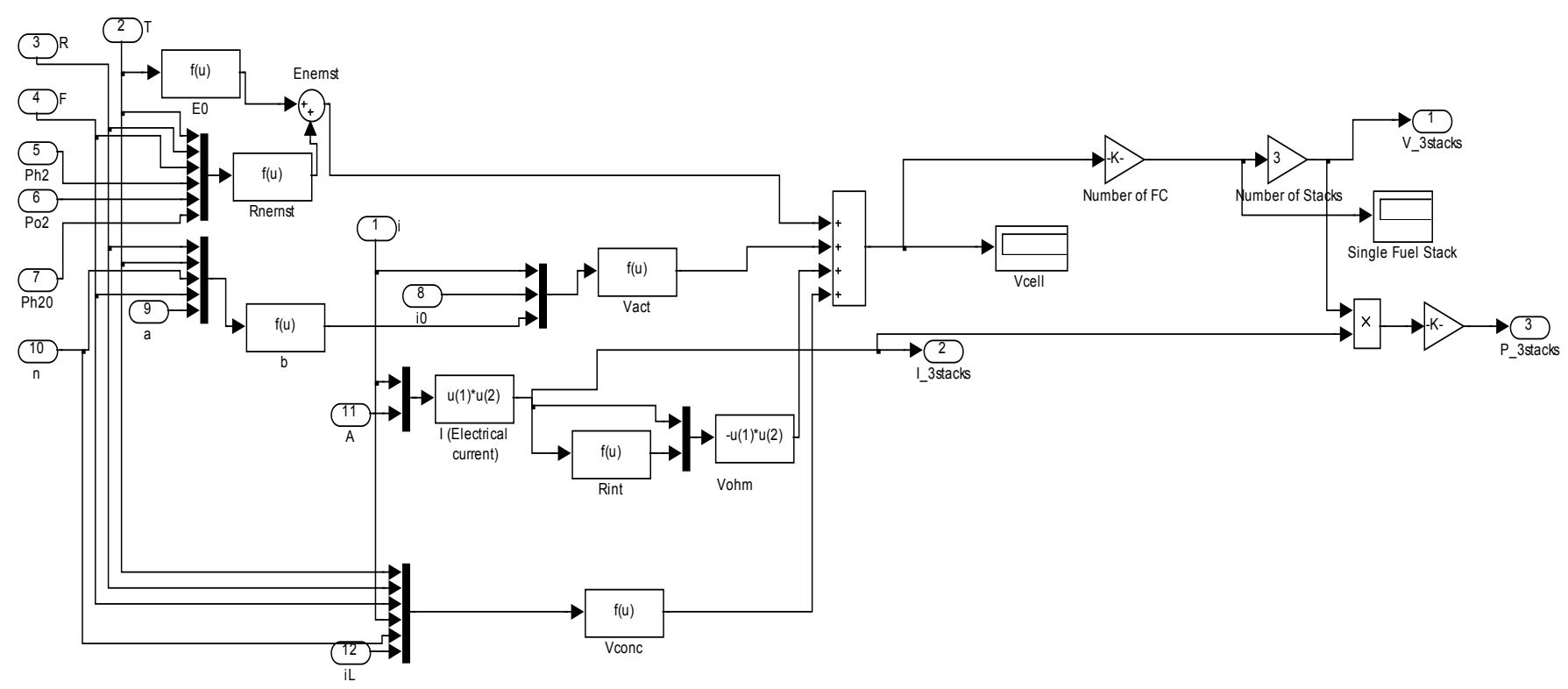

Fig. 6. 'Fuel Cell eqns' subsystem block 
TABLE II: RESULTS FOR THE PAFC DYNAMIC MODEL

\begin{tabular}{|c|c|c|c|c|c|c|c|c|c|}
\hline $\mathrm{R}(\Omega)$ & $\mathrm{I}_{-3 \text { 3stacks }}(\mathrm{A})$ & $\mathrm{V}_{-3 \text { 3stacks }}(\mathrm{V})$ & $\mathrm{P}_{-3 \text { 3stacks }}(\mathrm{KW})$ & $\mathrm{I}_{\mathrm{dc}}(\mathrm{A})$ & $\mathrm{V}_{\mathrm{dc}}(\mathrm{V})$ & $\mathrm{P}_{\mathrm{dc}}(\mathrm{KW})$ & $\mathrm{I}_{\mathrm{ac}}(\mathrm{A})$ & $\mathrm{V}_{\mathrm{ac}}(\mathrm{V})$ & $\mathrm{P}_{\mathrm{ac}}(\mathrm{KW})$ \\
\hline 2.2 & 587.3 & 861.4 & 505.9 & 586.9 & 872.1 & 511.8 & 276.2 & 647.3 & 309.7 \\
\hline 4 & 348.7 & 930.1 & 324.4 & 348.6 & 933.4 & 325.4 & 164 & 698.7 & 198.5 \\
\hline 9 & 166.2 & 998.4 & 165.9 & 165.8 & 1009 & 167.3 & 78.24 & 750.1 & 101.7 \\
\hline
\end{tabular}

In Fig. 7, the 'Con of sim blocks to pow blocks' subsystem block maintains the connection between the simulink blocks and the power system blocks. It converts the simulink signal (V_3stacks, stack voltage for three stacks) into 'simpowersystem' block eligible signal through the controlled voltage source block. There is a rectifier diode after the controlled voltage source block in this subsystem block to connect to power system blocks. The current measurement and voltage measurement blocks measure the current and voltage, respectively. The mean blocks are connected to calculate the mean value of current and voltage. The dc power is calculated by multiplying the mean value of current and voltage. The power value is converted into kilowatt $(\mathrm{kW})$ unit through a gain block. Thus the subsystem block has four outputs which are dc outputs for current, voltage and power and diode current.

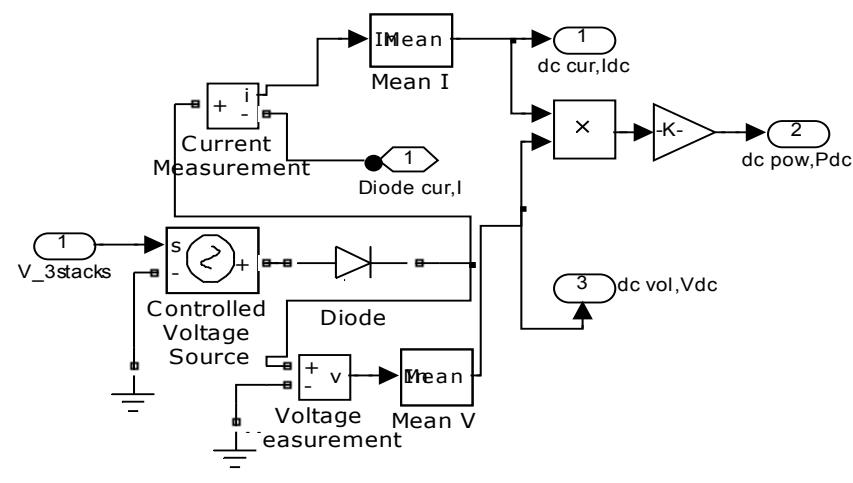

Fig. 7. 'Con of sim blocks to pow blocks' subsystem block

The dc current, voltage and power can be observed through display and scope block in fig.4. A series RLC branch is connected with the diode current from the 'Con of sim blocks to pow blocks' subsystem block and then grounded. The resistance and inductance values are very small compared to the capacitance value in the RLC branch. The value of resistance is taken small to keep the power loss small through this path. A small amount of inductance value helps to block the ac current through this path. A large amount of capacitance value is used to smooth the dc current. After the series RLC branch, the positive port of an inverter is connected to convert the dc signal into ac signal and the negative port is grounded. The inverter is IGBT type and it has three bridge arms (A, B \& C) which are connected to 'Measurements' subsystem block. There is a PWM generator input $(\mathrm{g})$ to the inverter which is a pure ac source. Since the 'internal generating of modulating signal' of the PWM generator block is marked, no reference input current signal is provided. So the wave shapes look like ideal PWM wave shapes.

One feedback of dc current from 'Con of sim blocks to pow blocks' subsystem block is connected to the 'Feedback' subsystem block. Fig. 8 shows the 'Feedback' subsystem block. Here the feedback current (I) is converted into current density (i) through a gain block to provide it as an input to the model. The memory block is used to store the initial condition i.e. to specify minimum current density to observe the results.

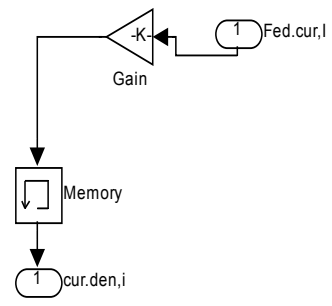

Fig. 8. 'Feedback' subsystem block

In Fig. 9, the 'Measurements' subsystem block can be observed. The inputs of this block are the outputs of the inverter i.e. A, B \& C bridge arms. In this subsystem, these three bridge arms are connected to the three phase V-I measurement (phase-to-phase type) block. The $\mathrm{V}_{\mathrm{abc}}$ and $\mathrm{I}_{\mathrm{abc}}$ port are connected to the RMS blocks to calculate the root mean square (rms) values of voltage and current. Then the rms voltage and current values are demuxed into three so that each phase voltage and each phase current for the three phase setup can be observed. $\mathrm{V}_{\mathrm{ph} 1}, \mathrm{~V}_{\mathrm{ph} 2} \& \mathrm{~V}_{\mathrm{ph} 3}$ are the phase voltages and $\mathrm{I}_{\mathrm{ph} 1}, \mathrm{I}_{\mathrm{ph} 2} \& \mathrm{I}_{\mathrm{ph} 3}$ are the phase currents. One phase voltage is multiplied to one phase current which makes the phase power. But this phase power is converted to line power in kilowatt $(\mathrm{kW})$ unit through a gain block. The $\mathrm{a}, \mathrm{b}, \& \mathrm{c}$ ports of three phase V-I measurement block are the outputs of this subsystem.

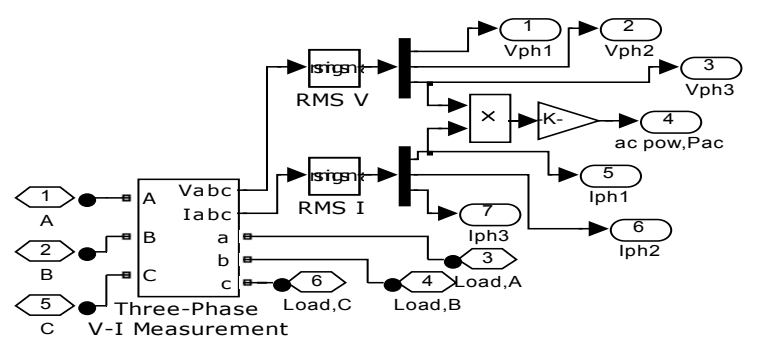

Fig. 9. 'Measurements' subsystem block

In Fig. 4, the outputs of 'Measurements' block are connected to a three phase parallel RLC branch acting as a resistive load. The outputs of the load is connected together and grounded. The $\mathrm{I}_{\mathrm{ac}}, \mathrm{V}_{\mathrm{ac}} \& \mathrm{P}_{\mathrm{ac}}$ display blocks show the ac current, voltage and power, respectively. The scope block shows the phase voltages, phase currents and line power curves in ac with respect to time. A powergui block is used in fig.4 to run the model with simple power system blocks.

\section{Simulation Results AND Discussions}

The dynamic model is simulated for 1 second to observe the results. Table II shows the results for different values of load. 


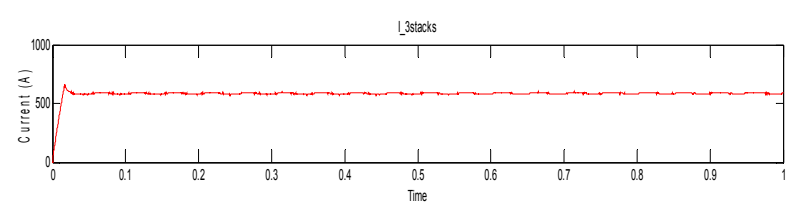

V_sstacks
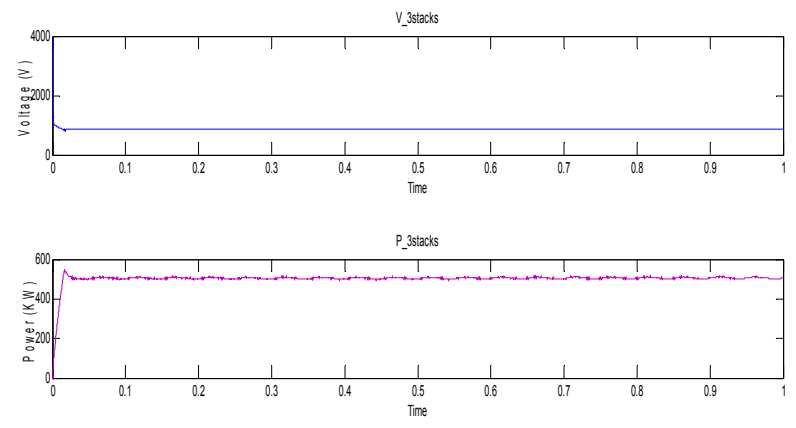

Fig. 10. Stack current, voltage, and power as a function of time

This table shows that the values of stack current (I_3stacks) and dc current $\left(\mathrm{I}_{\mathrm{dc}}\right)$ are almost similar and the values of ac current $\left(I_{a c}\right)$ are less than the half of $I_{-}$3stacks or $I_{d c}$ for each value of $\mathrm{R}$. The values of stack voltages $\left(\mathrm{V}_{-}\right.$3stacks $)$and $\mathrm{dc}$ voltages $\left(\mathrm{V}_{\mathrm{dc}}\right)$ are also similar but ac voltages $\left(\mathrm{V}_{\mathrm{ac}}\right)$ less than the $\mathrm{V}_{\text {_stacks }}$ or $\mathrm{V}_{\mathrm{dc}}$. The same characteristic is observed in case of power. The power loss is observed between the dc power and ac power because of the inverter power loss and absence of filter.

In Fig.10, the initial transient of I_3stacks, V_3stacks, and P_3stacks can be observed through the 'I, V, \& P' scope block of the dynamic model with respect to time.

Fig. 11 shows the initial transient and steady state values for same parameters with respect to time. These wave shapes can be observed through the 'dc' scope block of the model.
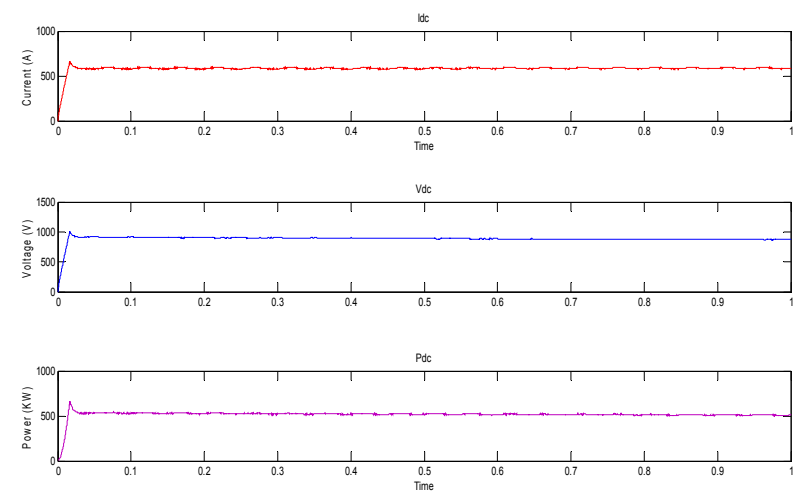

Fig. 11. DC current, voltage, and power as a function of time

Fig. 12 shows the wave shapes for ac parameters. The wave shapes for phase currents and phase voltages are not shown here since the ac current $\&$ ac voltage wave shapes in Fig. 12 are one of the phase currents and voltages, respectively.

Fig. 10 - Fig. 12 are the outputs for the load $R=2.2 \Omega$. Same observations are found for other loads but in different range of values. So only these figures are discussed here. All of the current curves increases initially and then goes almost to a steady state value. Same characteristic is found in case of power. But the stack voltage shows decreasing nature at the beginning and then almost linear. The dc and ac voltages also show the similar characteristic i.e. increasing nature at the beginning and then almost linear nature.
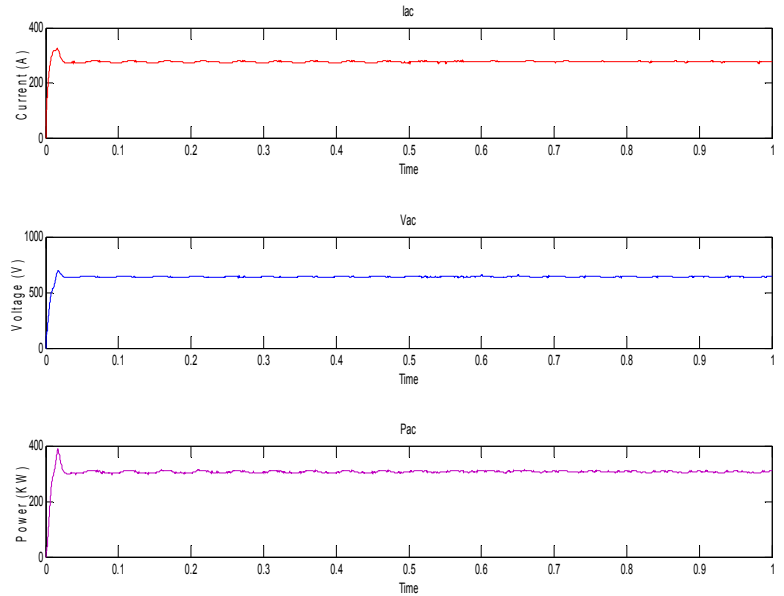

Fig. 12. AC current, voltage, and power values

\section{CONCLUSION}

In this paper the dynamic modeling of a PAFC fuel cell system and its associated power electronics is presented. Simulation results are discussed at different stages of the model. In future, further analysis can be done by connecting the ac power to the grid and by designing a controller for the whole model to deliver some required power.

\section{ACKNOWLEDGMENT}

M. A. Tanni and Dr. M. T. Iqbal thank the UTC power for financial support of this research.

\section{REFERENCES}

[1] A. Kirubakaran, S. Jain, and R. K. Nema (April 2009). A review on fuel cell technologies and power electronic interface. Renewable and Sustainable Energy Reviews. vol. 13. pp. 2430-2440. [Online]. Available: http://www.elsevier.com/locate/rser.

[2] F. A. O. Berenguer and M. G. Molina. (December 2009). Design of improved fuel cell controller for distributed generation systems. International Journal of Hydrogen Energy. vol. 35. pp. 5974- 5980. [Online]. Available: http://www.elsevier.com/locate/he

[3] W. Choi, P. N. Enjeti, and J. W. Howze, "Development of an equivalent circuit model of a fuel cell to evaluate the effects of inverter ripple current," IEEE, 2004.

[4] T. Asaeda, T. Yutani, T. Kawabata, and Y. Hamasaki, "Dc-to-ac power converter for fuel cell system," IEEE, 1983.

[5] Fuel Cell Handbook, $7^{\text {th }}$ ed., EG\&G Technical Services, Inc., Morgantown, West Virginia, 2004, pp. 1-7.

[6] P. L. Zervas, M. K. Koukou, and N. C. Markatos (March 2006). Predicting the effects of process parameters on the performance of phosphoric acid fuel cells using a 3-D numerical approach. Energy Conversion and Management. vol. 47. pp. 2883-2899. [online]. Available: http://www.elsevier.com/locate/enconman.

[7] M. J. Khan and M. T. Iqbal, "Modelling and analysis of electrochemical, thermal and reactant flow dynamics for a PEM fuel cell system," Fuel Cells, November, 2004.

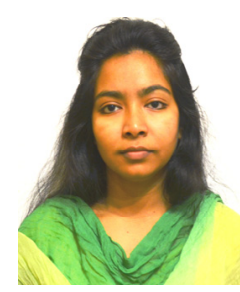

M. A. Tanni was born in Dhaka, Bangladesh. She is currently a full time graduate student at Memorial University of Newfoundland, Canada. She is doing her masters in the Department of Engineering and Applied Science. Her major is electrical and she is studying on thesis based program under the supervision of Dr. Tariq Iqbal. Her research topics is related to fuel cell. She is a student member of IEEE. She has obtained her bachelor degree in Electrical and Electronic Engineering (EEE) from Khulna University of Engineering \& Technology (KUET), Bangladesh.

She worked on renewable energy field on her undergraduate program. Her thesis topic was related to solar cell. At that time, she worked on a journal 
paper and three conference papers which are already published. Her current research interest is fuel cell related.

She achieved the second prize in a paper competition from KUET Excellence Foundation (KFS) at the time of undergraduate.

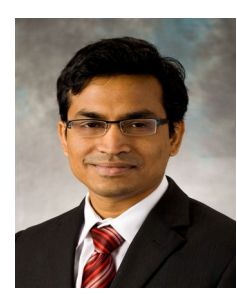

Md Arifujjaman was born in Khulna, Bangladesh on January 12, 1979. He received the B.Sc. Eng. degree in electrical and electronic engineering from the Khulna University of Engineering and Technology (KUET), Khulna, Bangladesh, in 2002, and the M.Eng. and Ph.D. degrees in electrical engineering from the Memorial University of Newfoundland, St. John's, NL, Canada, in 2006 and 2010 , respectively.

During 2010-2011, he was a Post Doctoral Fellow with the Faculty of Engineering, University of New Brunswick. He is currently a Senior Research Engineer - Power Electronics with UTC Power, South Windsor, CT, USA. His industrial experience in power conversion includes research and development at the Khulna University of Engineering and Technology, Nalcor Energy, The Partnership Group for Science and Engineering (PAGSE), and UTC Power, where he developed high-density dc-dc power converters, grid tied wind and solar inverters, and digital controllers using DSPs. His research interests include power electronics reliability, maximum power point tracking algorithm, wind turbine, fuel cell, and high-performance power converters topologies. His current research activities are supported by the UTC Power. He is the technical point of contact on power electronics research between UTC Power and Massachusetts Institute of Technology (MIT), Texas A \& M University, Rensselaer Polytechnic Institute (RPI) in USA and Memorial University of Newfoundland (MUN), Canada.

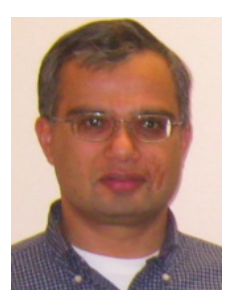

M. Tariq Iqbal received the B.Sc.(EE) degree from the University of Engineering and Technology, Lahore in 1986, the M. Sc. Nuclear Engineering degree from the Quaid-e-Azam University, Islamabad in 1988 and the Ph.D. degree in Electrical Engineering from the Imperial College London in 1994. From 1988 to 1991 and again from 1995 to 1999 he worked at the Pakistan Institute of Engineering and Applied Science, Islamabad, Pakistan. From 1999 to 2000 he worked as an Associate Professor at IIEC, Riphah International University. Since 2001 he is working at Faculty of Engineering and Applied Science, Memorial University of Newfoundland. Presently he is a full Professor. His teaching activities cover a range of electrical engineering topics including electronics devices, control systems, renewable energy systems and power electronics. Currently, his research focuses on modeling and control of renewable energy systems with interests in the areas of design of control systems and comparison of control strategies of hybrid energy systems. 